\title{
Evaluation of efficacy and safety of artesunate and its active metabolite, dihydroartemisinin, in streptozotocin-induced diabetes rats by blood pharmacokinetic analysis
}

\author{
Keizo Fukushima ${ }^{\dagger}$, Yousuke Uchimura $^{\dagger}$, Akira Okada $^{\dagger}$ and Nobuyuki Sugioka* \\ *Correspondence: nsugioka@pharm.kobegakuin.ac.jp

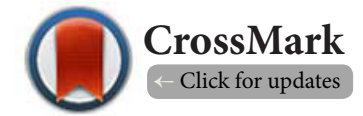

†These autohrs contributed equally to this work.

Department of Clinical Pharmacokinetics, Faculty of Pharmaceutical Sciences, Kobe Gakuin University, Chuo-ku, Kobe 650-8586, Japan.

\begin{abstract}
Background: Artesunate (AS), an anti-malarial drug, is hydrolyzed by serum esterase for its conversion to the active metabolite, dihydroartemisinin (DHA). Evidence for the clinical effectiveness of AS is growing; however, little information is available on special populations such as patients with diabetes mellitus (DM). In addition, although erythrocytes are considered as a target site, the blood pharmacokinetics of AS and DHA remain unclear. Therefore, the blood pharmacokinetics of AS and DHA were investigated in DM rats in the present study.

Methods: DM rats were prepared by intraperitoneal injection of streptozotocin. An in vitro protein binding study of AS and DHA was performed by the ultrafiltration method. Plasma and blood samples were collected after the intravenous administration of AS, to analyze pharmacokinetics of AS and DHA. Blood to plasma ratios (BP ratio), as an index of erythrocyte distribution, were then calculated by dividing blood concentrations by plasma concentrations.

Results: The protein bindings of AS and DHA were $83.7 \%$ and $92.6 \%$ in control rats and $86.2 \%$ and $92.2 \%$ in DM rats, respectively. All concentration profiles in this study were best fit by a two compartment model; the plasma and blood pharmacokinetic parameters of AS and DHA in DM rats were not significantly different from those in control rats. The BP ratio of AS was at an extremely low level (approximately 0.5) just after its administration, whereas that of DHA was maintained above 1.0 throughout the study; however, no significant changes were observed between control and DM rats.

Conclusion: The glycation of albumin with DM did not affect the protein bindings of AS or DHA. No significant changes were observed in the conversion of AS to DHA by serum esterase or disposition of DHA in DM rats. The blood concentrations of DHA declined in parallel with plasma concentrations and the distribution of DHA to erythrocytes was good. In conclusion, the efficacy and safety of both AS and DHA were tolerated in DM rats with DHA having more favorable characteristics than AS.
\end{abstract}

Keywords: Artesunate, dihydroartemisinin, pharmacokinetics, erythrocyte, diabetes mellitus

\section{Introduction}

Malaria is a life-threatening infection that still has a high morbidity and mortality in low-latitude regions such as subSaharan Africa and India [1,2]. The prevalence of diabetes mellitus (DM) is also high, and the number of DM patients in the world is expected to approximately double between 2000 and 2030 [3]. Along with recent demographic growth and urbanization, marked increases have been reported in the number of DM patients in sub-Saharan Africa and India [4-6]. DM patients were previously shown to be at relatively high risk not only of common infections but also malaria, and this was partly attributed to the decrease in T cell-mediated immunity in these patients $[\mathbf{7 , 8}]$. Therefore, the increase in the number of DM patients infected with malaria is a cause for concern.

Artemisinin-based combination therapy (ACT) is recently recommended as a first-line treatment for malaria in order to prevent malaria parasites developing resistance, and is commonly based on the combination of an artemisinin derivative with a conventional anti-malarial drug $[9,10]$. Artesunate (AS) is one of the most widely used artemisinin derivatives; AS itself has little activity in malaria parasites, but is rapidly converted to the active metabolite, dihydroartemisinin (DHA), by serum esterase in the systemic circulation. AS has been intensively investigated among the artemisinin derivatives for its usefulness and the ACT regimen with AS has been shown to improve the clinical outcomes of patients $[11,12]$. However, despite growing evidence to support its clinical effectiveness, the effects of AS and DHA have not yet been investigated in detail in special populations such as DM patients.

Hyperglycemia with DM affects not only the physiological condition of the patient but also often the pharmacokinetics of a drug; the non-enzymatic glycation of serum albumin was shown to influence the protein binding of certain drugs, which is one of the most important factors for the distribution of drugs 
Fukushima et al. Interactive Medicinal Chemistry 2014,

[13], and the activities/expressions of serum esterases and drug-metabolizing enzymes were also shown to be altered in DM $[14,15]$. These alterations have the ability to affect the pharmacokinetics of AS and DHA. In addition, although erythrocytes are considered as the target site of AS and DHA, their blood concentrations had never been quantified until a study performed by Lindegardh et al., [16]; in the extraction procedure, cations derived from hemoglobin $\left(\mathrm{Fe}^{2+}\right)$ degrade the reactive peroxide bridges of their structures. Therefore, the blood pharmacokinetics of AS and DHA are also limited.

To assess their safety and efficacy in DM, the present study investigated the blood pharmacokinetics of AS and DHA, with a focus on their distribution to erythrocytes. We here reported the protein bindings, plasma and blood pharmacokinetics following the intravenous administration, and blood to plasma ratios (BP ratio) of AS and DHA as an index of erythrocyte distribution in streptozotocin-induced DM rats.

\section{Methods \\ Materials}

Artesunate (AS) and dihydroartemisinin (DHA) were purchased from Tokyo Chemical Industry Co., Ltd. (Tokyo, Japan). Streptozotocin (mixed anomers), potassium dichromate, and ammonium acetate were purchased from Nacalai Tesque Inc. (Kyoto, Japan) and deferoxamine mesylate was obtained from Sigma-Aldrich Co. (MO, USA). A commercially available injectable formulation of AS, ASTIR ${ }^{\circledR}$ (Ranbaxy Laboratories Ltd., Delhi, India) was used as a dosing solution of AS. Methanol, acetonitrile and all other reagents were of analytical grade and were used without further purification.

\section{Animal preparations and biochemical tests}

All animal experiments were performed in accordance with the Guidelines for Animal Experimentation of Kobe Gakuin University. Male Wistar rats of 11 weeks old (weighing 250 10 g) were obtained from Nippon SLC Co., Ltd. (Hamamatsu, Japan). Rats were maintained in a temperature-controlled facility with a $12 \mathrm{hr}$ light/dark cycle for at least 5 days with free access to food and water before use. Diabetes mellitus model rats (DM rats, $n=6$ ) were induced by the intraperitoneal administration of streptozotocin solution at a dose of 50 $\mathrm{mg} / \mathrm{kg}(1 \mathrm{~mL} / \mathrm{kg})$, which was prepared by dissolving by icecold saline just before use; control rats $(n=5)$ received the same volume of ice-cold saline. All rats were fed a normal rodent diet for 6 days and then fasted overnight. The next day, namely 1 week after the intraperitoneal administration of streptozotocin, blood samples for biochemical tests $(0.4$ $\mathrm{mL}$ ) were taken from tail vein and centrifuged at $9000 \mathrm{~g}$ for $10 \mathrm{~min}$ to obtain plasma; $100 \mu \mathrm{L}$ of plasma was used to determine blood sugar (BS) levels with the glucose test kit (Glucose C2 Test Wako, Wako Pure Chemical Industries Ltd., Osaka, Japan) and residual plasma was frozen at $-80^{\circ} \mathrm{C}$ until the measurement of albumin (Alb), glycoalbumin (GA), and total protein (TP) by a commercial laboratory, Oriental Yeast
Co., Ltd (Tokyo, Japan). Rats were then used in a subsequent pharmacokinetic study as described later.

\section{In vitro protein binding study of AS and DHA}

The protein bindings of AS and DHA were simultaneously determined by the traditional ultrafiltration method; under light anesthesia with diethylether, whole blood collected by cardiac puncture from control $(n=4)$ and DM $(n=4)$ rats was prepared in the same way as that described above, and plasma was then obtained by centrifugation at $9000 \mathrm{~g}$ for 10 min. The mixed solution of AS and DHA in methanol $(10 \mu \mathrm{g} / \mathrm{mL}$, respectively) was spiked into control or DM plasma to yield a final concentration at $0.4 \mu \mathrm{g} / \mathrm{mL}$. The spiked plasma was then incubated for $20 \mathrm{~min}$ at $37^{\circ} \mathrm{C}$. A total of $50 \mu \mathrm{L}$ of incubated plasma was immediately frozen at $-80^{\circ} \mathrm{C}$ until analysis and $500 \mu \mathrm{L}$ of residual plasma was placed in an ultrafiltration unit, Amicon ${ }^{\circledR}$ Ultra-0.5mL 3K (Merck KGaA, Darmstadt, Germany). After centrifugation for $10 \mathrm{~min}$ at $12000 \mathrm{~g}$ and $4^{\circ} \mathrm{C}, 50 \mu \mathrm{L}$ of filtrate was collected and stored at $-80^{\circ} \mathrm{C}$ until analysis. The protein bindings of AS and DHA were calculated by dividing filtrate concentrations by plasma concentrations.

\section{Pharmacokinetic study of AS and DHA}

The dosing solution of AS (10 $\mathrm{mg} / \mathrm{mL})$ was prepared just before use according to the product information of $A S T I R^{\circledR}$; $60 \mathrm{mg}$ of AS powder was dissolved in $1 \mathrm{~mL}$ of bicarbonate $(5 \%$, $\mathrm{w} / \mathrm{v}$ ) and the mixture was then added to $5 \mathrm{~mL}$ of saline. Under anesthesia induced by the intraperitoneal administration of $50 \mathrm{mg} / \mathrm{kg}$ sodium pentobarbital, control $(\mathrm{n}=5)$ and DM $(n=6)$ rats were administered the AS dosing solution at a dosage of $10 \mathrm{mg} / \mathrm{kg}$ via the right jugular vein. Blood samples $(0.25 \mathrm{~mL})$ were obtained from the left jugular vein at $5,15,30,45,60$, $90,120,180$, and 240 min after dosing and were transferred to heparinized centrifuge tubes. A total of $50 \mu \mathrm{L}$ of blood was immediately transferred to another centrifuge tube containing $10 \mu \mathrm{L}$ of $0.4 \mathrm{M}$ potassium dichromate and stored at $-80^{\circ} \mathrm{C}$ for at least 4 days to stabilize the blood [16]. Residual blood was centrifuged at $9000 \mathrm{~g}$ for $10 \mathrm{~min}$ to obtain plasma samples, which were also immediately stored at $-80^{\circ} \mathrm{C}$ until analysis as described below.

Simultaneous determination of AS and DHA in plasma, filtrate, and blood samples by liquid chromatography tandem mass spectrometry (LC/MS/MS)

AS and DHA concentrations in plasma and filtrate samples were determined by a previously reported method with some modifications [17,18]; the combined stock solutions of AS and DHA were prepared by dissolving in methanol ranging from 0.02 to $200 \mu \mathrm{g} / \mathrm{mL}$. Aliquots of the combined stock solutions were stored as a quality control (QC) and the remainders served as a working solution; the combined working solutions of AS and DHA were stable for at least 3 months (>95\%). Calibration samples were prepared by spiking working solutions into drugfree plasma or filtrate with a 20 -fold dilution (viz., 0.001 to 10 
$\mu \mathrm{g} / \mathrm{mL}$ ). A total of $50 \mu \mathrm{L}$ of calibration and unknown samples were added to $100 \mu \mathrm{L}$ acetonitrile for protein precipitation, and were then vortexed and centrifuged at $9000 \mathrm{~g}$ for $10 \mathrm{~min}$, $4^{\circ} \mathrm{C}$. The supernatant was transferred to a $2.0 \mathrm{~mL}$ centrifugal tube, added to $1.7 \mathrm{~mL}$ of diethylether, vortexed for $30 \mathrm{sec}$, and centrifuged at $9000 \mathrm{~g}$ for $10 \mathrm{~min}, 4^{\circ} \mathrm{C}$. The organic layer was then transferred to a new tube and evaporated at room temperature under a vacuum using the centrifugal evaporator, CVE-2000 (EYELA, Tokyo, Japan). The residue was reconstituted with $150 \mu \mathrm{L}$ of the mobile phase $(20 \mathrm{mM}$ ammonium formate: acetonitrile $=1: 9, \mathrm{v} / \mathrm{v}$ ) and $50 \mu \mathrm{L}$ was then injected into the LC/MS/MS system. Blood concentrations were determined by a previously reported method with some modifications [16]. To prevent hemolysis when spiking, the combined stock solutions of AS and DHA for the blood assay were prepared by dissolving in $50 \%$ drug-free plasma, not methanol. The calibration samples for the blood assay $(0.001$ to $10 \mu \mathrm{g} / \mathrm{mL})$ were prepared by spiking working solutions into drug-free blood and immediately added to $0.4 \mathrm{M}$ potassium dichromate $(20 \%, v / v)$; to prevent AS and DHA from degradation by $\mathrm{Fe}^{2+}$ derived from hemoglobin, $\mathrm{Fe}^{2+}$ in blood was oxidized to $\mathrm{Fe}^{3+}$ by the addition of potassium dichromate [16]. After stabilization at $-80^{\circ} \mathrm{C}$ for at least 4 days, calibration and unknown samples were thawed on ice and $50 \mu \mathrm{L}$ was then added to $50 \mu \mathrm{L}$ of $0.08 \mathrm{M}$ potassium dichromate and $50 \mu \mathrm{L}$ of $20 \mathrm{mg} / \mathrm{mL}$ deferoxamine, which forms a stable chelate with $\mathrm{Fe}^{3+}$. After vortexing, the mixture was added to $300 \mu \mathrm{L}$ acetonitrile for protein precipitation. The following extraction with diethylether, reconstitution with the mobile phase, and injection into the LC/MS/MS system were the same procedures as those described in the plasma and filtrate assay. The LC/MS/ MS system consisted of the 2690 Separation Module (Waters Co., MA, USA), Micromass Quattro Ultima Pt Mass Spectrometer (Waters Co., MA, USA), and the operation software, MassLynx Version 4.1 (Waters Co., MA, USA). The analytical column for the separation of AS and DHA was a Quicksorb ODS $(2.1 \mathrm{~mm}$ i.d., $150 \mathrm{~mm}, 5 \mu \mathrm{m}$ size, Chemco, Osaka, Japan). Elution was performed isocratically at a flow rate of $0.2 \mathrm{~mL} / \mathrm{min}$ with the mobile phase ( $20 \mathrm{mM}$ ammonium formate: acetonitrile $=1: 9$, $\mathrm{v} / \mathrm{v})$. Mass spectrometric detection was performed utilizing electrospray ionization in the positive ion mode (ESI+) by the multiple reaction monitoring mode (MRM) with ion transitions of 402.0 to $267.0 \mathrm{~m} / \mathrm{z}$ for AS and 302.1 to $163.2 \mathrm{~m} / \mathrm{z}$ for DHA. The source temperature, dissolvation temperature, and corn voltage were set at $130^{\circ} \mathrm{C}, 200^{\circ} \mathrm{C}$, and $45 \mathrm{~V}$, respectively. The lower limit of quantitation was independent of sample matrixes: $0.001 \mu \mathrm{g} / \mathrm{mL}$ for AS and less than $0.001 \mu \mathrm{g} / \mathrm{mL}$ for $\mathrm{DHA}$, respectively.

\section{Pharmacokinetic analysis}

The obtained plasma or blood concentration profiles of both AS and DHA were fit to a one or two compartment model using Phoenix WinNonlin version 6.3 software (Certara, GK, USA). The compartment model and weighting were evaluated by the Akaike's information criteria (AIC) and Goodness-of-fit diagnostic plots (i.e., predicted vs observed concentration and weighted residual vs observed concentration plots). With a conventional two-compartment model, the distribution volume of the central and peripheral compartments of AS were represented by $V_{1}$ and $V_{2}$, respectively, whereas those of DHA were corrected by the metabolized fraction $\left(F_{m}\right)$ from AS: $V_{1} / F_{m}$ and $V_{2} / F_{m}$. The intercompartmental rate constants and elimination rate constant from the central compartment were expressed as $k_{12}$ and $k_{21^{\prime}}$ and $k_{e l^{\prime}}$ respectively; the half-life of distribution and elimination phase were denoted as $t_{1 / 2 a}$ and $t_{1 / 2 \beta^{\prime}}$ respectively. The area under the plasma or blood concentration vs. time curve from 0 to infinity (AUC) was calculated by integrating the predicted concentration of the central compartment. The distribution to erythrocytes was evaluated by the blood to plasma concentration ratio (BP ratio), which was calculated by dividing blood concentrations by plasma concentrations at the corresponding time points.

\section{Statistical analysis}

All values are expressed as the mean \pm standard error (S.E.). Differences in means were compared with the Mann-Whitney $\mathrm{U}$ test using the software, SPSS version 21 (IBM SPSS Statistics, IBM Co., NY, USA); differences were assumed to be significant at $p<0.05$.

\section{Results}

The biochemical parameters and in vitro protein binding of AS and DHA in control and streptozotocin-induced DM model rats were shown in Table 1. Significant increases in BS (387\%) and GA (206\%) were observed in DM rats with a decrease in body weight (82\%); however, no significant changes were observed in Alb or TP. In the in vitro protein binding study, the degradation of AS and corresponding conversion into

Table 1. Biochemical tests and in vitro protein binding of AS and DHA in control and DM rats.

\begin{tabular}{llll}
\hline & Control & DM & $P$ value \\
\hline Biochemical parameters & & & \\
\hline Body weight (g) & $262.4 \pm 1.2$ & $215.3 \pm 1.9$ & 0.004 \\
BS (mg/dL) & $145.1 \pm 4.8$ & $561.3 \pm 9.9$ & 0.004 \\
Alb (g/dL) & $3.86 \pm 0.06$ & $3.76 \pm 0.04$ & 0.792 \\
GA (g/dL) & $0.53 \pm 0.01$ & $1.09 \pm 0.03$ & 0.004 \\
TP (g/dL) & $5.22 \pm 0.07$ & $4.97 \pm 0.05$ & 0.429 \\
\hline Protein binding & & & \\
\hline AS (\%) & $83.7 \pm 0.4$ & $86.2 \pm 0.7$ & 0.200 \\
DHA (\%) & $92.6 \pm 0.2$ & $92.2 \pm 0.2$ & 0.686 \\
\hline
\end{tabular}

BS: blood sugar. Alb: albumin. GA: glycoalbumin. TP: total protein.

Each value represents the mean \pm S.E. of control $(n=5)$ and DM $(n=6)$ rats for biochemical parameters, and control $(n=4)$ and DM $(n=4)$ rats for protein binding. ${ }^{a}$ protein binding studies were performed at a nominal concentration of $0.4 \mu \mathrm{g} / \mathrm{mL}$ Differences in the means were tested using the Mann-Whitney $U$ test. 
Fukushima et al. Interactive Medicinal Chemistry 2014,

http://www.hoajonline.com/journals/pdf/2053-7107-2-1.pdf

DHA were observed after incubating control plasma spiked with $A S$ and DHA at a final concentration of $0.4 \mu \mathrm{g} / \mathrm{mL}$ for 20 $\mathrm{min} ; 0.312 \pm 0.03 \mu \mathrm{g} / \mathrm{mL}$ in AS and $0.460 \pm 0.08 \mu \mathrm{g} / \mathrm{mL}$ in DHA (mean \pm standard deviation of $n=4$ ). However, these values were not significantly different from those after incubation for 5 min (data not shown). No significant difference was observed in protein binding between control and DM plasma after incubation for $20 \mathrm{~min}$ at a nominal concentration of $0.4 \mu \mathrm{g} / \mathrm{mL}$ of $\mathrm{AS}$ and $\mathrm{DHA}$; however the protein binding of DHA was higher than that of AS. The plasma and blood concentration profiles of AS were depicted in Figure 1; plasma and blood concentrations in both control and DM rats were below the lower limit of quantitation at $120 \mathrm{~min}$ after the administration of AS. Figure 2 shows the plasma and blood concentration profiles of DHA. The obtained plasma and blood pharmacokinetic parameters of AS and DHA were summarized in Tables 2 and $\mathbf{3}$, respectively. The plasma and blood concentrations of both AS and DHA in control and DM rats declined in a bi-phasic manner; all the profiles obtained in the present study were best fit by a two compartment

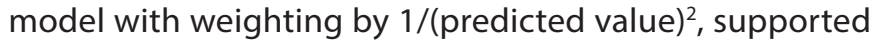
by minimum AIC and best Goodness-of-fit profiles (data not shown). The plasma concentration profiles of AS were very similar in control and DM; however, no significant differences

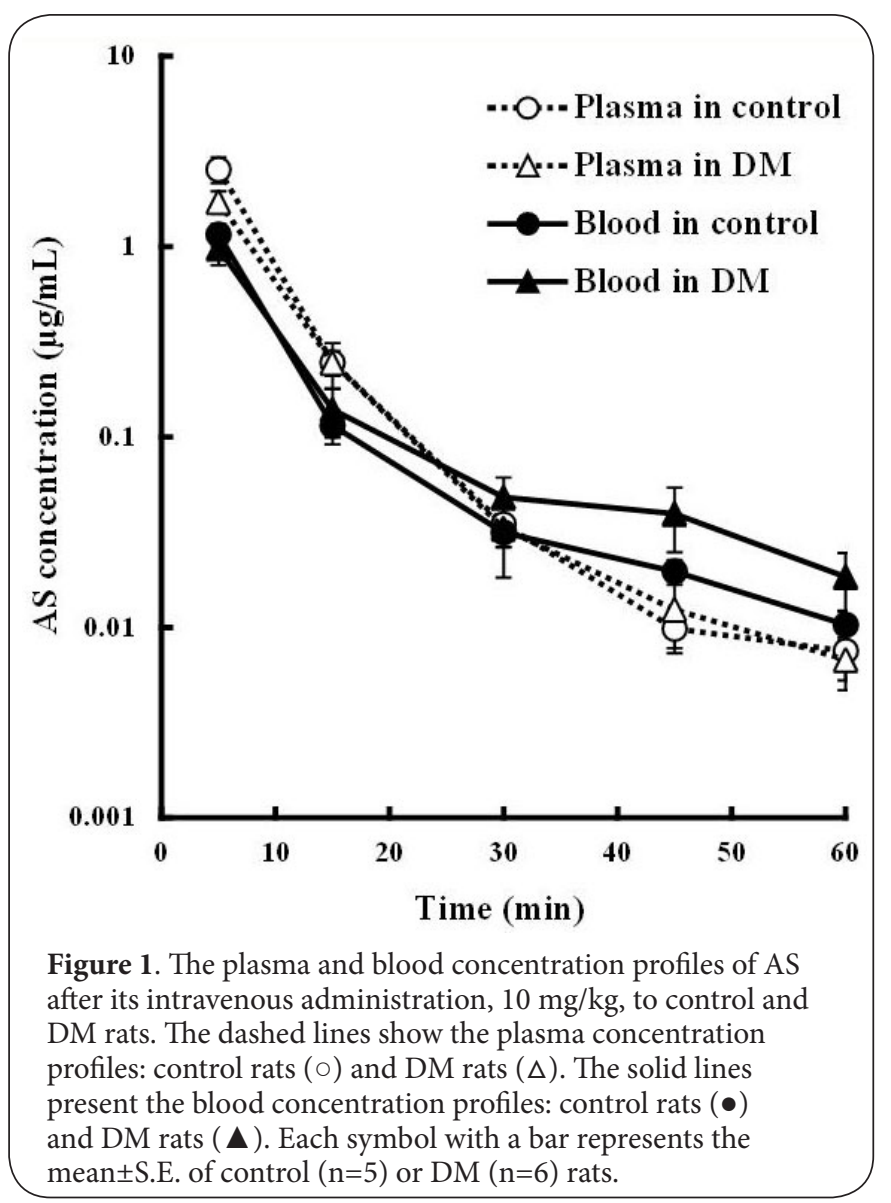

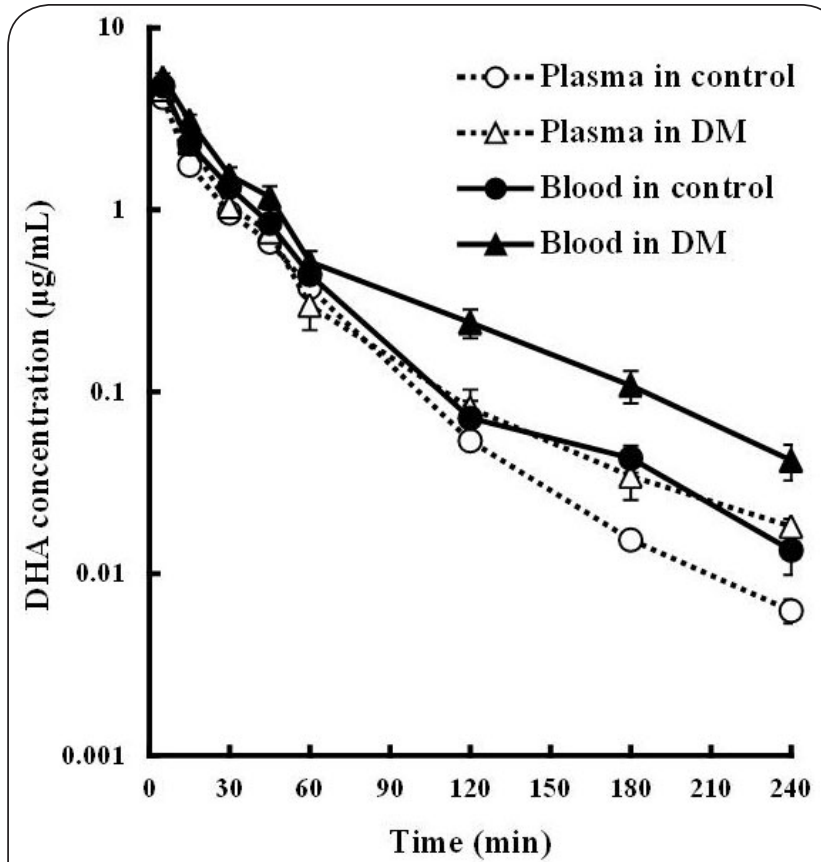

Figure 2. The plasma and blood concentration profiles of DHA after its intravenous administration of AS, $10 \mathrm{mg} / \mathrm{kg}$, to control and DM rats. The dashed lines show the plasma concentration profiles: control rats $(0)$ and DM rats $(\Delta)$. The solid lines presented the blood concentration profiles: control rats $(\bullet)$ and DM rats $(\boldsymbol{\Delta})$. Each symbol with a bar represents the mean \pm S.E. of control $(n=5)$ or DM $(n=6)$ rats.

were observed in plasma pharmacokinetic parameters, except for $\mathrm{V}_{1}$. The blood concentrations of AS in control and DM rats were lower than the corresponding plasma concentrations until 15 min after its administration, but subsequently increased; however, no significant differences were observed in blood pharmacokinetic parameters between control and DM rats. The plasma concentration profiles of DHA in control and DM were also very similar rats and no significant differences were observed between any plasma pharmacokinetic parameter of DHA. DHA concentrations in the blood were continuously higher than those in the plasma; the area under the blood concentration of DHA was slightly higher in DM rats. The blood to plasma (BP) ratio vs time curve of $A S$ and DHA was shown in Figures 3 and $\mathbf{4}$, respectively. The BP ratios of AS in control and DM rats were low (approximately 0.5 ) until 15 min after its administration, but gradually increased to approximately 2-4 at $60 \mathrm{~min}$, when no significant difference was observed in the $\mathrm{BP}$ ratio between control and DM rats at any sampling time point. In contrast, the BP ratio of DHA in DM rats was significantly higher than that of control rats 120 min after dosing only.

\section{Discussion}

The aim of the present study was to investigate the plasma and blood pharmacokinetics of AS and DHA in DM rats. The DM 
Fukushima et al. Interactive Medicinal Chemistry 2014,

Table 2. Plasma and blood pharmacokinetics of AS after the intravenous administration of $\mathrm{AS}, 10 \mathrm{mg} / \mathrm{kg}$, to control and DM rats.

\begin{tabular}{|c|c|c|c|}
\hline & Control & DM & $P$ value \\
\hline \multicolumn{4}{|c|}{ Plasma pharmacokinetics } \\
\hline $\mathrm{V}_{1}(\mathrm{~mL})$ & $634 \pm 153$ & $916 \pm 142$ & 0.004 \\
\hline $\mathrm{V}_{2}(\mathrm{~mL})$ & $164 \pm 52$ & $290 \pm 64$ & 0.247 \\
\hline $\mathrm{k}_{12}(1 / \min )$ & $0.0121 \pm 0.0042$ & $0.0083 \pm 0.0016$ & 0.329 \\
\hline $\mathrm{k}_{21}(1 / \min )$ & $0.0461 \pm 0.0110$ & $0.0302 \pm 0.0068$ & 0.931 \\
\hline $\mathrm{k}_{\mathrm{el}}(1 / \min )$ & $0.248 \pm 0.022$ & $0.207 \pm 0.021$ & 0.429 \\
\hline$t_{1 / 2 \alpha}(\min )$ & $2.76 \pm 0.32$ & $3.33 \pm 0.34$ & 0.247 \\
\hline $\mathrm{t}_{1 / 2 \beta}(\min )$ & $19.3 \pm 3.9$ & $40.4 \pm 17.7$ & 0.177 \\
\hline AUC $(\mu \mathrm{g} / \mathrm{mL} \cdot \mathrm{min})$ & $19.0 \pm 3.1$ & $12.5 \pm 1.7$ & 0.329 \\
\hline \multicolumn{4}{|c|}{ Blood pharmacokinetics } \\
\hline $\mathrm{V}_{1}(\mathrm{~mL})$ & $1315 \pm 309$ & $1295 \pm 264$ & 0.715 \\
\hline $\mathrm{V}_{2}(\mathrm{~mL})$ & $1411 \pm 564$ & $2201 \pm 722$ & 0.662 \\
\hline $\mathrm{k}_{12}(1 / \min )$ & $0.0297 \pm 0.0027$ & $0.0553 \pm 0.0085$ & 0.052 \\
\hline $\mathrm{k}_{21}(1 / \min )$ & $0.0367 \pm 0.0068$ & $0.0405 \pm 0.0069$ & 0.931 \\
\hline $\mathrm{k}_{\mathrm{el}}(1 / \min )$ & $0.246 \pm 0.032$ & $0.223 \pm 0.019$ & 0.537 \\
\hline $\mathrm{t}_{1 / 2 \alpha}(\min )$ & $2.63 \pm 0.35$ & $2.47 \pm 0.18$ & 0.931 \\
\hline $\mathrm{t}_{1 / 2 \beta}(\min )$ & $26.8 \pm 7.4$ & $25.3 \pm 3.8$ & 0.584 \\
\hline $\operatorname{AUC}(\mu \mathrm{g} / \mathrm{mL} \cdot \min )$ & $9.08 \pm 0.93$ & $8.61 \pm 1.57$ & 0.715 \\
\hline
\end{tabular}

$\mathrm{V}_{1}, \mathrm{~V}_{2}$ : distribution volume of the central or peripheral compartment. $\mathrm{k}_{12}, \mathrm{k}_{21}$ : transfer rate constant from the central to peripheral or peripheral to central compartment. kel: elimination rate constant from the central compartment. $t_{1 / 2 \alpha}$, $t_{1 / 2 \beta}$ : half-life of the distribution or elimination phase. AUC: area under the plasma or blood concentration vs. time curve from 0 to infinity. Each value represents the mean \pm S.E. of control $(n=5)$ and DM $(n=6)$ rats. Differences in the means were tested using the Mann-Whitney $\mathrm{U}$ test.

model rats used in this study were prepared by the traditional method using streptozotocin, which selectively impairs the beta cells of the pancreas [19], and were confirmed to have DM by elevations in blood sugar and glycoalbumin (Table 1).

The protein bindings of AS and DHA in control rats in the present study ( $83.7 \%$ and $92.6 \%$, respectively) were not significantly different from those in DM rats (Table 1 ), whereas these values were slightly higher than those in previous studies using radiolabeled AS and DHA (73-81\% and $76-82 \%)[20,21]$. Joseph et al., investigated the effect of the glycation of albumin on its binding to warfarin, which is often used as a probe compound for Sudlow site I, and reported no significant changes in the binding affinity of warfarin to glycated albumin, whereas a 4.7-5.8 fold increase in the binding affinity to glycated albumin was observed in L-tryptophan, a probe for Sudlow site II [13]. Bian et al., examined the interaction between artemisinin and albumin and demonstrated that artemisinin could bind to site I [22]. Taking these findings and the structural similarities between of AS and DHA to artemisinin into consideration, AS and DHA
Table 3. Plasma and blood pharmacokinetics of DHA after the intravenous administration of AS, $10 \mathrm{mg} / \mathrm{kg}$, to control and DM rats.

\begin{tabular}{|c|c|c|c|}
\hline & Control & DM & $P$ value \\
\hline \multicolumn{4}{|c|}{ Plasma pharmacokinetics } \\
\hline $\mathrm{V}_{\mathrm{l}} / \mathrm{F}_{\mathrm{m}}(\mathrm{mL})$ & $663 \pm 144$ & $580 \pm 53$ & 0.931 \\
\hline $\mathrm{V}_{2} / \mathrm{F}_{\mathrm{m}}(\mathrm{mL})$ & $352 \pm 110$ & $243 \pm 21$ & 0.931 \\
\hline $\mathrm{k}_{12}(1 / \mathrm{min})$ & $0.0420 \pm 0.0288$ & $0.0058 \pm 0.0008$ & 0.792 \\
\hline $\mathrm{k}_{21}(1 / \mathrm{min})$ & $0.0299 \pm 0.0111$ & $0.0133 \pm 0.0009$ & 0.429 \\
\hline $\mathrm{k}_{\mathrm{el}}(1 / \mathrm{min})$ & $0.0659 \pm 0.0162$ & $0.0454 \pm 0.0025$ & 0.537 \\
\hline $\mathrm{t}_{1 / 2 a}(\min )$ & $10.9 \pm 3.3$ & $13.1 \pm 0.6$ & 0.931 \\
\hline$t_{1 / 2 \beta}(\min )$ & $56.8 \pm 19.4$ & $62.5 \pm 3.9$ & 0.247 \\
\hline $\operatorname{AUC}(\mu \mathrm{g} / \mathrm{mL} \cdot \min )$ & $52.5 \pm 1.8$ & $59.6 \pm 5.4$ & 0.537 \\
\hline \multicolumn{4}{|c|}{ Blood pharmacokinetics } \\
\hline $\mathrm{V}_{\mathrm{l}} / \mathrm{F}_{\mathrm{m}}(\mathrm{mL})$ & $736 \pm 104$ & $447 \pm 35$ & 0.052 \\
\hline $\mathrm{V}_{2} / \mathrm{F}_{\mathrm{m}}(\mathrm{mL})$ & $382 \pm 129$ & $305 \pm 36$ & 0.931 \\
\hline $\mathrm{k}_{12}(1 / \mathrm{min})$ & $0.0064 \pm 0.0016$ & $0.0170 \pm 0.0027$ & 0.009 \\
\hline $\mathrm{k}_{21}(1 / \mathrm{min})$ & $0.0154 \pm 0.0039$ & $0.0259 \pm 0.0052$ & 0.082 \\
\hline $\mathrm{k}_{\mathrm{el}}(1 / \mathrm{min})$ & $0.0419 \pm 0.0016$ & $0.0398 \pm 0.0023$ & 0.429 \\
\hline$t_{1 / 2 a}(\min )$ & $13.8 \pm 1.1$ & $10.5 \pm 0.8$ & 0.052 \\
\hline $\mathrm{t}_{1 / 2 \beta}(\min )$ & $76.4 \pm 25.7$ & $50.3 \pm 4.1$ & 0.662 \\
\hline $\mathrm{AUC}(\mu \mathrm{g} / \mathrm{mL} \cdot \mathrm{min})$ & $65.1 \pm 9.5$ & $88.2 \pm 8.4$ & 0.052 \\
\hline \multicolumn{4}{|c|}{$\begin{array}{l}\mathrm{V}_{1}, \mathrm{~V}_{2}: \text { distribution volume of the central or peripheral } \\
\text { compartment. Fm: metabolized fraction into DHA. } \mathrm{k}_{12} \text {, } \\
\mathrm{k}_{21} \text { : transfer rate constant from the central to peripheral or } \\
\text { peripheral to central compartment. kel: elimination rate } \\
\text { constant from the central compartment. } \mathrm{t}_{1 / 2 \alpha}, \mathrm{t}_{1 / 2 \beta}: \text { half-life of the } \\
\text { distribution or elimination phase. AUC: area under the plasma } \\
\text { or blood concentration vs. time curve from } 0 \text { to infinity. Each } \\
\text { value represents the mean } \pm \text { S.E. of control }(n=5) \text { and DM }(n=6) \\
\text { rats. Differences in the means were tested using the Mann- } \\
\text { Whitney U test. }\end{array}$} \\
\hline
\end{tabular}

can also bind to site I of albumin; therefore, their bindings to albumin may not be affected by its glycation.

Many studies have investigated pharmacokinetic modeling for AS and DHA: non-, one-, and two-compartment and parent-metabolite simultaneous modeling [23-26]. The parent-metabolite (AS-DHA) simultaneous modeling was also applied in this study, but failed to fit the data or stabilize the parameters because the conversion of AS to DHA after its intravenous administration was too fast to accurately evaluate the conversion rate, namely the absorption rate constant (ka) of DHA; therefore, the pharmacokinetic analysis of AS and DHA were performed separately. The plasma and blood pharmacokinetic parameters of AS in DM rats were not significantly different from those in control rats, expect for $V_{1}$ in plasma (Figure 1 and Table 2). Although the distribution volume of AS in DM rats was slightly higher in plasma pharmacokinetics, no notable changes were observed in the in vitro protein binding and blood pharmacokinetics parameters of AS in DM rats (Tables 1 and 2); therefore, DM may not have a marked influence on the distribution of AS. Patel et al., 


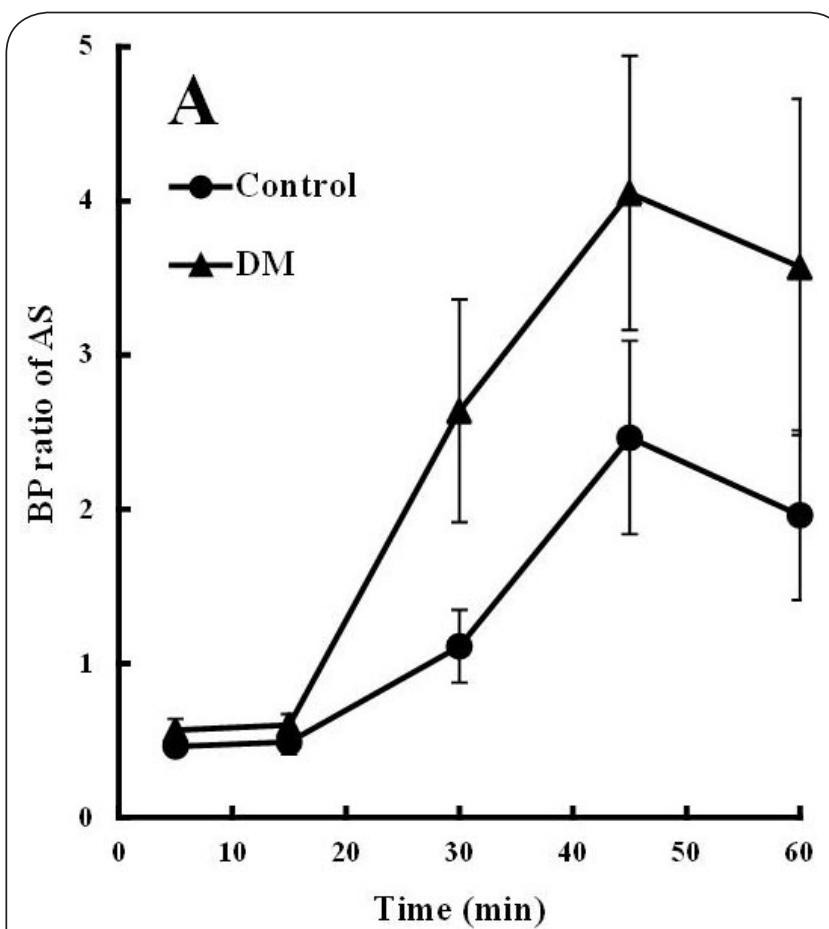

Figure 3. The blood to plasma (BP) ratio vs. time curves of AS after its intravenous administration of AS, $10 \mathrm{mg} / \mathrm{kg}$, to control $(\bullet)$ and DM rats $(\boldsymbol{\Delta})$. Each symbol with a bar represents the mean \pm S.E. of control $(n=5)$ or DM $(n=6)$ rats.

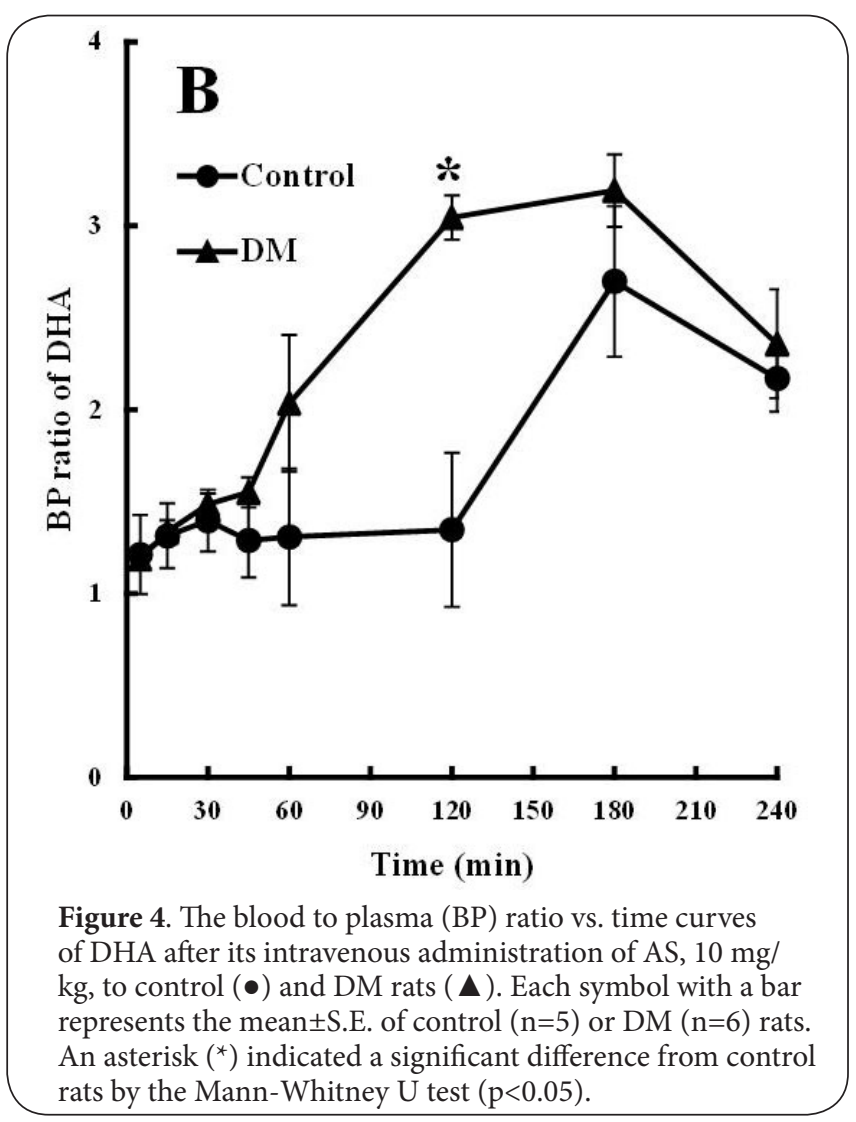

investigated the activities of serum esterases in streptozotocininduced DM rats and reported that pseudocholinesterase and paraoxonase activities were significantly higher $(250 \%)$ and lower (36\%) in DM rats, respectively, whereas no significant difference was observed in carboxylesterase activity, which mainly hydrolyzes AS [14]. Carboxylesterase has been shown to be highly expressed in rats [27]; therefore, DM may not have a significant effect on the conversion of AS to DHA by carboxylesterase, or its change in DM can be negligible. Similar to $A S$, no notable change was observed in the pharmacokinetic parameters of DHA in DM rats, whereas the AUC of blood was slightly increased in DM (Figure 2 and Table 3). After its conversion from AS, DHA is not oxidized by cytochrome-P450, but is glucuronidated by the UDP-glucuronosyltransferases $1 \mathrm{~A} 9$ and $2 \mathrm{B7}$ (UGT1A9 and UGT2B7) in the liver [28,29]. Dostalek et al., investigated the effect of DM on glucuronidation by UGT1 A9 and UGT2B7 in the human liver and showed that the expression and activity of UGT2B7, but not of UGT1A9, were significantly decreased in DM [30]; however, the effect of DM on DHA disposition was not significant in rats in the present study.

The BP ratios of AS in both control and DM rats were very close to the theoretical minimum value immediately following the intravenous administration of AS, (approximately 0.45 , Figure 3), which indicated that AS may not be distributed to a marked extent in erythrocytes in the early phase. This result raises another implication that the terminal phase of AS may not be the elimination phase, but the re-distribution phase to plasma fraction; namely, it was highly likely that the flipflop phenomenon may occur in rats, although insufficient evidence was collected in this study. In comparison to the early phase, the BP ratio of AS was relatively high in the terminal phase; therefore, AS was considered to have a high affinity for erythrocytes. However, AS has disadvantages over DHA not only in its pharmacological activity but also in its pharmacokinetic disposition due to its distribution delay and low concentration in erythrocytes. In contrast to AS, the BP ratios of DHA in both control and DM rats were maintained above 1.0 throughout the sampling period (Figure 4); the distribution of DHA to erythrocytes may be good. In addition, $t_{1 / 2 a}$ and $t_{1 / 2 \beta}$ for plasma were closed to those for blood (Table 3), and thus, it may be reasonable to monitor DHA plasma concentrations in order to evaluate its anti-malarial efficacy.

In the present study, however, no significant changes were observed in the BP ratio profiles of both AS and DHA in DM rats. There was another limitation in this study, separate to species differences; DM rats were used 1 week after the intraperitoneal administration of streptozotocin in this study. A previous study showed that it took approximately 5 weeks to increase the level of glycated hemoglobin (namely, hemoglobin A1c) in streptozotocin-induced DM rats [31]. Vattanaviboon et al., reported that the binding of DHA to hemoglobins accounted for $40-70 \%$ of the total uptake and each DHA molecule could bind with a $\beta$-globin dimer [32]. Therefore, the glycation of 
Fukushima et al. Interactive Medicinal Chemistry 2014,

hemoglobins has the potential to affect the localization of drugs in erythrocytes. However, further studies are warranted because the present study could not confirm this.

\section{Conclusions}

The glycation of albumin with DM did not affect the protein bindings of AS and DHA. In addition, the conversion of AS to DHA by serum esterase and the disposition of DHA also showed no significant changes in DM rats. Blood concentrations of DHA declined in parallel with plasma concentrations and the distribution of DHA to erythrocytes was good. In conclusion, the efficacy and safety of both AS and DHA is tolerated in DM rats and DHA has more favorable characteristics than AS.

\section{Competing interests}

The authors declare that they have no competing interests.

\section{Authors' contributions}

\begin{tabular}{|l|c|c|c|c|}
\hline Authors' contributions & KF & YU & AO & NS \\
\hline Research concept and design & $\checkmark$ & -- & -- & $\checkmark$ \\
\hline Collection and/or assembly of data & $\checkmark$ & $\checkmark$ & $\checkmark$ & -- \\
\hline Data analysis and interpretation & $\checkmark$ & $\checkmark$ & $\checkmark$ & $\checkmark$ \\
\hline Writing the article & $\checkmark$ & -- & -- & -- \\
\hline Critical revision of the article & $\checkmark$ & -- & -- & -- \\
\hline Final approval of article & $\checkmark$ & $\checkmark$ & $\checkmark$ & $\checkmark$ \\
\hline Statistical analysis & $\checkmark$ & -- & -- & -- \\
\hline
\end{tabular}

Acknowledgement

The present study has no specific grant from any funding agency. This manuscript was revised for language corrections by Medical English Service, Kyoto, Japan.

\section{Publication history}

Editors: Oliver Grundmann, University of Florida, USA.

Dong Xiao, University of Pittsburgh School of Medicine, USA.

Received: 06-Jan-2014 Revised: 12-Feb-2014

Accepted: 17-Feb-2014 Published: 28-Feb-2014

\section{References}

1. Sullivan D. Uncertainty in mapping malaria epidemiology: implications for control. Epidemiol Rev. 2010; 32:175-87. | Article I PubMed Abstract I PubMed Full Text

2. Landoh ED, Tchamdja P, Saka B, Tint KS, Gitta SN, Wasswa P and Christiaan de J. Morbidity and mortality due to malaria in Est Mono district, Togo, from 2005 to 2010: a times series analysis. Malar J. 2012; 11:389. | Article | PubMed Abstract | PubMed Full Text

3. Wild S, Roglic G, Green A, Sicree R and King H. Global prevalence of diabetes: estimates for the year $\mathbf{2 0 0 0}$ and projections for 2030. Diabetes Care. 2004; 27:1047-53. | Article | PubMed

4. Kumar P, Mallik D, Mukhopadhyay DK, Sinhababu A, Mahapatra BS and Chakrabarti P. Prevalence of diabetes mellitus, impaired fasting glucose, impaired glucose tolerance, and its correlates among police personnel in Bankura District of West Bengal. Indian J Public Health. 2013; 57:24-8. | Article | PubMed

5. Kengne AP, Echouffo-Tcheugui JB, Sobngwi E and Mbanya JC. New insights on diabetes mellitus and obesity in Africa-part 1: prevalence, pathogenesis and comorbidities. Heart. 2013; 99:979-83. | Article | PubMed

6. Kengne AP, Sobngwi E, Echouffo-Tcheugui JB and Mbanya JC. New insights on diabetes mellitus and obesity in Africa-Part 2: prevention, screening and economic burden. Heart. 2013; 99:1072-7. | Article | PubMed

7. Muller LM, Gorter KJ, Hak E, Goudzwaard WL, Schellevis FG, Hoepelman $\mathrm{Al}$ and Rutten GE. Increased risk of common infections in patients with type 1 and type 2 diabetes mellitus. Clin Infect Dis. 2005; 41:281-8. | Article | PubMed

8. Danquah I, Bedu-Addo $\mathrm{G}$ and Mockenhaupt FP. Type 2 diabetes mellitus and increased risk for malaria infection. Emerg Infect Dis. 2010; 16:1601-4. | Article | PubMed Abstract | PubMed Full Text

9. Davis TM, Karunajeewa HA and llett KF. Artemisinin-based combination therapies for uncomplicated malaria. Med J Aust. 2005; 182:181-5. I Article I PubMed

10. Setiawan B. Current malaria management: guideline 2009. Acta Med Indones. 2010; 42:258-61. | Pdf | PubMed

11. Smithuis F, Kyaw MK, Phe O, Win T, Aung PP, Oo AP, Naing AL, Nyo MY, Myint NZ, Imwong M, Ashley E, Lee SJ and White NJ. Effectiveness of five artemisinin combination regimens with or without primaquine in uncomplicated falciparum malaria: an open-label randomised trial. Lancet Infect Dis. 2010; 10:673-81. | Article | PubMed Abstract | PubMed Full Text

12. Ndounga M, Mayengue PI, Casimiro PN, Loumouamou D, Basco LK, Ntoumi F and Brasseur P. Artesunate-amodiaquine efficacy in Congolese children with acute uncomplicated falciparum malaria in Brazzaville. Malar J. 2013; 12:53. | Article | PubMed Abstract | PubMed Full Text

13. Joseph KS and Hage DS. The effects of glycation on the binding of human serum albumin to warfarin and L-tryptophan. J Pharm Biomed Anal. 2010; 53:811-8. | Article | PubMed Abstract | PubMed Full Text

14. Patel BN, Mackness MI, Harty DW, Arrol S, Boot-Handford RP and Durrington PN. Serum esterase activities and hyperlipidaemia in the streptozotocin-diabetic rat. Biochim Biophys Acta. 1990; 1035:113-6. | Article I PubMed

15. Hasegawa $Y$, Kishimoto $S$, Shibatani N, Nomura H, Ishii $Y$, Onishi M, Inotsume N, Takeuchi $Y$ and Fukushima $S$. The pharmacokinetics of morphine and its glucuronide conjugate in a rat model of streptozotocin-induced diabetes and the expression of MRP2, MRP3 and UGT2B1 in the liver. $J$ Pharm Pharmacol. 2010; 62:310-4. | Article | PubMed

16. Lindegardh N, Hanpithakpong W, Kamanikom B, Pattayaso J, Singhasivanon P, White NJ and Day NP. Quantification of dihydroartemisinin, artesunate and artemisinin in human blood: overcoming the technical challenge of protecting the peroxide bridge. Bioanalysis. 2011; 3:161324. | Article | PubMed

17. Hanpithakpong W, Kamanikom B, Dondorp AM, Singhasivanon P, White NJ, Day NP and Lindegardh N. A liquid chromatographic-tandem mass spectrometric method for determination of artesunate and its metabolite dihydroartemisinin in human plasma. J Chromatogr B Analyt Technol Biomed Life Sci. 2008; 876:61-8. | Article | PubMed

18. He G, Qi H, Wang M, Yang J, Wen F, Wang W, Qiao C and Zhang H. LC-MS/ MS method for the simultaneous quantitation of three active components derived from a novel prodrug against schistosome infection. $J$ Pharm Biomed Anal. 2013; 83:186-93. | Article | PubMed

19. Junod A, Lambert AE, Stauffacher W and Renold AE. Diabetogenic action of streptozotocin: relationship of dose to metabolic response. J Clin Invest. 1969; 48:2129-39. | Article | PubMed Abstract | PubMed Full Text

20. Li Q, Xie LH, Haeberle A, Zhang J and Weina P. The evaluation of radiolabeled artesunate on tissue distribution in rats and protein binding in humans. Am J Trop Med Hyg. 2006; 75:817-26. | Article | PubMed

21. Xie LH, Li Q, Zhang J and Weina PJ. Pharmacokinetics, tissue distribution and mass balance of radiolabeled dihydroartemisinin in male rats. Malar J. 2009; 8:112. | Article | PubMed Abstract | PubMed Full Text

22. Bian $\mathrm{H}$, Li M, Yu Q, Chen Z, Tian J and Liang $\mathrm{H}$. Study of the interaction of artemisinin with bovine serum albumin. Int J Biol Macromol. 2006; 39:291-7. | Article | PubMed

23. Batty KT, Thu LT, Davis TM, llett KF, Mai TX, Hung NC, Tien NP, Powell SM, Thien HV, Binh TQ and Kim NV. A pharmacokinetic and pharmacodynamic study of intravenous vs oral artesunate in uncomplicated 
Fukushima et al. Interactive Medicinal Chemistry 2014,

http://www.hoajonline.com/journals/pdf/2053-7107-2-1.pdf

falciparum malaria. Br J Clin Pharmacol. 1998; 45:123-9. | Article | PubMed Abstract | PubMed Full Text

24. Tarning J, Rijken MJ, McGready R, Phyo AP, Hanpithakpong W, Day NP, White NJ, Nosten F and Lindegardh N. Population pharmacokinetics of dihydroartemisinin and piperaquine in pregnant and nonpregnant women with uncomplicated malaria. Antimicrob Agents Chemother. 2012; 56:1997-2007. | Article | PubMed Abstract | PubMed Full Text

25. Tan B, Naik H, Jang IJ, Yu KS, Kirsch LE, Shin CS, Craft JC and Fleckenstein L. Population pharmacokinetics of artesunate and dihydroartemisinin following single- and multiple-dosing of oral artesunate in healthy subjects. Malar J. 2009; 8:304. | Article | PubMed Abstract | PubMed Full Text

26. Morris CA, Onyamboko MA, Capparelli E, Koch MA, Atibu J, Lokomba V, Douoguih M, Hemingway-Foday J, Wesche D, Ryder RW, Bose C, Wright L, Tshefu AK, Meshnick S and Fleckenstein L. Population pharmacokinetics of artesunate and dihydroartemisinin in pregnant and non-pregnant women with malaria. Malar J. 2011; 10:114. | Article | PubMed Abstract I PubMed Full Text

27. Bahar FG, Ohura K, Ogihara T and Imai T. Species difference of esterase expression and hydrolase activity in plasma. J Pharm Sci. 2012; 101:3979-88. | Article | PubMed

28. Mehlotra RK, Bockarie MJ and Zimmerman PA. Prevalence of UGT1A9 and UGT2B7 nonsynonymous single nucleotide polymorphisms in West African, Papua New Guinean, and North American populations. Eur J Clin Pharmacol. 2007; 63:1-8. | Article | PubMed Abstract | PubMed Full $\underline{\text { Text }}$

29. llett KF, Ethell BT, Maggs JL, Davis TM, Batty KT, Burchell B, Binh TQ, Thu le TA, Hung NC, Pirmohamed M, Park BK and Edwards G. Glucuronidation of dihydroartemisinin in vivo and by human liver microsomes and expressed UDP-glucuronosyltransferases. Drug Metab Dispos. 2002; 30:1005-12. | Article | PubMed

30. Dostalek M, Court MH, Hazarika S and Akhlaghi F. Diabetes mellitus reduces activity of human UDP-glucuronosyltransferase $2 \mathrm{~B} 7$ in liver and kidney leading to decreased formation of mycophenolic acid acyl-glucuronide metabolite. Drug Metab Dispos. 2011; 39:448-55. | Article | PubMed Abstract | PubMed Full Text

31. Gandhi GR and Sasikumar P. Antidiabetic effect of Merremia emarginata Burm. F. in streptozotocin induced diabetic rats. Asian Pac J Trop Biomed. 2012; 2:281-6. | Article | PubMed Abstract | PubMed Full Text

32. Vattanaviboon $P$, Wilairat $P$ and Yuthavong $Y$. Binding of dihydroartemisinin to hemoglobin $\mathrm{H}$ : role in drug accumulation and host-induced antimalarial ineffectiveness of alpha-thalassemic erythrocytes. $\mathrm{Mol}$ Pharmacol. 1998; 53:492-6. | Article | PubMed

\section{Citation:}

Fukushima K, Uchimura Y, Okada A and Sugioka $N$. Evaluation of efficacy and safety of artesunate and its active metabolite, dihydroartemisinin, in streptozotocin-induced diabetes rats by blood pharmacokinetic analysis. Interact Med Chem. 2014; 2:1. http://dx.doi.org/10.7243/2053-7107-2-1 